\title{
Study on Computer Information Management Method in File Management
}

\author{
Yonghong Li \\ Linyi University, Linyi Shandong 276005, China
}

Keywords: Computer, Information management, File management.

\begin{abstract}
The computer information management is a product of the era of knowledge economy and the information age, is also extremely important resource. Since the current extensive use of computer information technology, information management methods for the archives management in the integration and created a very good chance. Currently, the digital archive has become the consensus of the community and has achieved great results. Using computer technology to implement records management in the past has the great advantage of doing so it is difficult to manage opportunities, and improve management performance can be a good unit of archival work. This article describes the introduction of computer file management information management means outstanding advantages, analyzes the problems in archives management computer information management faced, and described the use of computer information management specific manner in file management.
\end{abstract}

\section{Introduction}

Digital archive information is the inevitable choice for sustainable development of archives cause. The introduction of computer-based management information in the file management, which greatly promoted the cause of great change file. The use of electronic records archives, archives (chamber) of the current social mainstream Tibetan archives digitization and networking has become. Archives (chamber) is one of China's information system resources extremely important component, is currently facing new challenges of the information age. Under the new situation, file management is no longer the need for cumbersome manual operation, but to make use of computer information management, which requires the majority of archivists to keep up with the pace of development, actively change the original mode of thinking, committed promote traditional file management information file to be converted to a modern mode.

\section{Outstanding advantages of file management introducing computer information management tools}

First, it can greatly enhance the utilization efficiency of the file. Most of our current grassroots archives (chamber) used in the computer information management more single development function is very simple, some grassroots archives (room) even confined to the archives, or by typing the computer Recording to store documents, As a result, will inevitably lead to inefficient records management, then there people, goods, money and a huge waste of time. Second, it can greatly shorten the overall secondary literature information processing time. Previous archive information processing personnel file is a typical way of working slowly and deliberately type, which is formed from the documentation to the development of secondary literature information, the overall longer length of time, failure information is prone to problems, so to will greatly affect the value of the use of archives has. In the realization of the Archives Information, Editorial and Research Staff just from your computer retrieval of electronic files, then use the features of your sort, process, will be able to very quickly and easily edit the secondary literature. Third, it can enhance the archives department and archivist position. By digitizing and electronic file management information, relevant information on results can be a duplicate copy of a computer, and will not affect the quality of electronic records, the copies sent out the results of Archives Compilation of relevant government departments and research institutions, so well to be able to enhance the social influence of archival 
work, but also to extend the range of archive services, to enhance the image and status of the archives department. Four is able to promote mutual integration of information and archives of new technologies. File management information can contribute to better information and files between the effective integration of new technologies. Archives should actively adapt to the current requirements + Internet is coming of age, so that archives play a greater value.

\section{Problems of computer information management existing in file management}

First, there are electronic records to identify the authenticity of the original problem. Because the electronic document is prone to be tampered with, but after the change can not leave any traces. Thus, at the time of the formation of archival material to use computers, it is difficult to draft people to leave their own unique handwriting of interest, and the unit responsible person is difficult to be issued in the electronic file, after a long time could not be more natural confirm whether or not the material is real. Even if it was because of some purpose to be changed, it can be hard to find. Second, there is the question whether the confidential contents of electronic records. Once the coupling network, all terminals can be retrieved to be stored in the network into electronic files, electronic documents and files can be copied and spread, so that it is easy to cause leakage of confidential content, and thus the safety of archives a threat. The third is whether the presence of long-term retention of electronic files. Because the current along with information technology continued to deepen, there have been more and more enterprises and institutions began to implement paperless office, all these documents are often stored in units into the network only needs to operate the computer search for relevant information. This method does make archival storage easier, but also to facilitate the practical use, however, if the network paralysis or hackers, viruses and other problems, there is a possibility these electronic document files to be deleted or destroyed, so that there will not be to make up for the huge losses.

\section{Specific applications of computer information management in file management}

First, implement automatic cataloging. In early1970s, some Western countries gradually applied computer technology to the field of records management. Project first appeared for automating file cataloging work, which in fact is one of the most currently used content. Using this technique, the hand searching for the original file is a considerable improvement. After years of development, it has become the Western countries automatically cataloged archives professional institutions and provide an important guarantee for the relevant files. Second, implement on-line automatic retrieval. In this way information is managed to be good at speaking in front of the automatic cataloging. This approach allows the user files faster and more directly related to the search for the required information itself. If divided by the scope of this retrieval methods can be divided into communications and traceability of formula and other two categories; if divided by computer use, the search methods can be divided into questions and answers and other batch-type two categories; if by memory take the way division, it can be divided into random and sequential retrieval categories. Third, the implementation of automated information files preparation process. Today, the archives user can already use the computer to aid in the completion of archival information thematic screening, and automatically archive material to provide the required access to personnel, and complete the editing, layout, and other work on this basis.

\section{Specific methods to strengthen computer information management in file management}

First, use network technology to create a network file system. To use the latest computer technology, especially network technology to develop suitable for professional archives information network, and the formation of the overall network through systematic lateral, longitudinal, and many other nodes can be contacted, and thus play the overall advantages and comprehensive ability.

The second is the development and implementation of the digital archive standard specification. Today, the actual situation of China's computer information archive is the normalization and 
standardization construction archives urgent need to upgrade, especially archive software are numerous and chaotic, which greatly affects the computer file and enhancing our overall level of information technology. Therefore, we must first clear the archives specific scope of work, to be strictly implemented, and is committed to do a good job standardization and standardization construction archives work.

Third, actively accelerate the process of building a database file. Construction of the new database system has been the subject of electronic archives of the central link, but also the archives information. File database fully rely on modern information technology for the possession of the unit file to implement scientific and efficient management. Building a database system is a necessary long-term unremitting efforts to complete the task, must be from low to high, from a single group to the progressive development process. I think the establishment of a database file must get the unit leadership attaches great importance to a unified understanding of the unit's staff, always do computer professionals and archivists mutual cooperation, and actively create a living library, through the flexible use of the database, strengthen the focus , to be developed from a single library system library. If the ability to enhance the construction of a database file with the unit construction destination library archives linked to each other, using the Internet to create a more open fractional database group, will be able to make automated performance profile information obtained new upgrade.

The fourth is to strengthen archives software development and promotion efforts. Archive electronic documents covering the contents of the file, vector display. Because a variety of factors, each unit of electronic files rely on software and hardware platforms are different, so that on how to integrate database file formation difficult. Therefore, we must attach great importance to adopt more proactive initiatives to be addressed. Through the issuance of electronic records database directory structure and interchange format, to be on the record level and file-level archive directory database field name, type, length, and other regulations, and effectively regulate the archive software and its data format to ensure the database can have a more accurate nature and effectiveness.

Fifth, we should fight for the introduction of laws and regulations to maintain the authenticity and validity of electronic documents. Currently, each creating an electronic document, modification, archiving, storage and processing, utilization and many other links among the information is to be falsified or even disappear there is a risk, even if we now have a very advanced modern information technology security, still need to have appropriate management measures to impose to ensure that it can be implemented. Therefore, the perfection of electronic documents relating to laws and regulations as well as the specific management procedures for the effective maintenance of electronic records has the originality and authenticity, to ensure their safety has a very important value. To take advantage of the legal form of the electronic record-keeping and the use of standards to be determined, so that people can be more consciously abide by the above provisions. At the same time, it should use the form of legislation to clarify the electronic documents and electronic records has the legal credentials of action in order to protect national archives administrations can lawfully electronic documents and electronic archives strict management.

Sixth, do archival information system necessary isolation. To ensure the security of the archive information system, enterprises and institutions can be implemented completely separate internal office network and the Internet between the unit between the internal office network and external network physical isolation is formed, thereby protecting the information can be in the respective range being used effectively avoid inner situation of cross each other outside the network appears. The first isolation layer mainly refers to the router through the implementation of reasonable settings to those address the lack of security clearance, etc. with the virus isolate. The second isolation layer mainly refers to reasonable network firewall settings. Most firewalls have filtered out of the network data, network access status management functions, so that it is possible to block some of the need to ban access to business when necessary, and the behavior of network attack detection and alarm. As a result, to protect the security of the unit to a computer network system through rational design closure.

Seven is to implement electronic document archiving process technology related work. Today, a large number of electronic files generated daily receive, process, exchange, dispose of, archiving, 
protection of electronic documents stored in the meta-quality information, grasp the source of the information and other electronic documents, it has become every archivists are sure to master the basic Work requirements. On this basis, archivists should also learn to quickly identify how to protect the original electronic document, how to ensure the reliability of electronic documents, how permanent preservation and long-term preservation of electronic records to implement regular backups to prevent loss of information occurs, effectively enhance understanding of computer hardware equipment and control, and be able to skillfully use the business to ensure that electronic documents and paper files also can reflect the proper value.

Eight is the construction of an electronic archive of information security assessment mechanism. For the storage medium is not stable enough to be eliminated backward technology, hacking or virus attack and many other reasons, it will lead to the security of electronic records under severe threat. Archives for information management, in order to solve the security problem of electronic records, it should identify the types of risks they face, the full implementation of the most detailed analysis and evaluation. Only the use of a standardized model and approach to the implementation of electronic records safety assessment, to be able to grasp the overall security situation in the interior, and in-depth analysis of various types of threats, and thus high-risk threat reasonable response, so that it is possible to effectively improve the overall security situation in the electronic file security assessment system, the real solid formation of electronic archive of information security assessment mechanism.

\section{Conclusions}

To sum up, in view of recent years, China's deepening reform comprehensively promote, archive this precious resource has also been more and more attention. Given the current competition in the market gradually, there have been more aware of the enterprises and institutions file management information of significance. File management in the traditional sense will mainly focus on the like personnel files, archives, science and technology archives preservation and management, it is certainly difficult to adapt to the new situation and higher requirements for unit management. However, because of the impact and the size and other aspects of the industry, the current level of our specific use of computer information management also jagged and high degree of information units have achieved full digital archives, information technology is not high degree of organization is still in the manual stage management of files among the resulting file management information having features cannot be fully realized. This requires that we effectively get rid of the constraints of traditional file management mode, actively integrate into the tide of information technology development, so that archives play a bigger and better value.

\section{References}

[1] Tang Lingna. On application of computer technology in file management. Heilongjiang File, 2012,3.

[2] Jiang Congcui. On application of file management and company files in computer technology. Consumer Electronics, 2012,6.

[3] Li Gangzhong. The use of computer technology in application of hospital archives management. Guide of China Medicine, 2012,30.

[4] Zhao Chunmiao. Computer technology in the application of the archives information management. Science and technology innovation and application, 2014,7.

[5] Yang Li. Computer technology in the application of the archives information management. Modern Economic Information, 2014,11.

[6] Zuo Xunan. Computer technology in the application of the archives information management. Heilongjiang Science and Technology Information, 2014,28. 